\title{
ATELLA
}

\section{Distribuição espacial dos casos de intoxicação por agrotóxicos agrícolas em diferentes monocultivos no estado de Goiás (2005-2015)}

\author{
Spatial distribution of cases of intoxication by agricultural pesticides \\ in different monocultures in the state of Goiás (2005-2015)
}

\section{Distribución espacial de los casos de intoxicación por agrotóxicos agrícolas en diferentes monocultivos en el estado de Goiás (2005-2015)}

\author{
Pedro Dias Mangolini Neves \\ Universidade Estadual de Maringá \\ pmangolini@hotmail.com
}

\author{
Marcelo Rodrigues Mendonça \\ Universidade Federal de Goiás \\ ufgmendonca@gmail.com
}

\begin{abstract}
Resumo
Os impactos do uso de agrotóxicos sobre o ambiente e a saúde humana têm merecido a atenção da comunidade científica no Brasil e, precisamente em Goiás, considerado um dos "celeiros agrícolas do país" nas últimas décadas. Neste artigo foram sistematizados e apresentados dados de intoxicação por agrotóxicos, no período de 2005 a 2015, estado de Goiás obtidos no Centro de Informação Toxicológica CIT/GO, que guarda as fichas de notificação compulsória de intoxicações por agrotóxicos, lotado na Superintendência de Vigilância Sanitária e Ambiental SUVISA de Goiás. Na análise da presença de monocultivos nos municípios, pode-se perceber uma relação perigosa entre o elevado número total de intoxicações por habitantes e a territorialização do agronegócio, principalmente, o cultivo de soja, milho e cana-de-açúcar.
\end{abstract}

Palavras-chave: Intoxicação; Agrotóxicos; Commodities agrícolas; Goiás.

\begin{abstract}
The impacts of the use of agrochemicals on the environment and human health have deserved the attention of the scientific community in Brazil and, in Goiás, considered one of the "agricultural barns of the country" in the last decades. In this article,
\end{abstract}


pesticide intoxication data were systematized and presented in the period from 2005 to 2015, state of Goiás, obtained at the Center for Toxicological Information CIT/GO), which keeps the compulsory notification of poisoning by pesticides, filled at the Superintendence of Surveillance Sanitary and Environmental - SUVISA of Goiás. In the analysis of the presence of monocultures in the municipalities, one can perceive a dangerous relationship between the high total number of intoxications per inhabitant and the territorialization of agribusiness, mainly soybean, corn and sugar cane cultivation.

Keywords: Intoxication; Pesticides; Agricultural commodities; Goiás.

\begin{abstract}
Resumen
Los impactos del uso de agrotóxicos sobre el ambiente y la salud humana han merecido atención de la comunidad científica en Brasil y, precisamente en Goiás, considerado uno de los "graneros agrícolas del país" en las últimas décadas. En este artículo se sistematizaron y presentaron datos de intoxicación por agrotóxicos, en el período de 2005 a 2015, estado de Goiás obtenidos en el Centro de Información Toxicológica - CIT/GO, que guarda las fichas de notificación obligatoria de intoxicaciones por agrotóxicos, abarrotado en la Superintendencia de Vigilancia Sanitaria y Ambiental - SUVISA de Goiás. En el análisis de la presencia de monocultivos en los municipios, se puede percibir una relación peligrosa entre el elevado número total de intoxicaciones por habitantes y la territorialización del agronegocio, principalmente, el cultivo de soja, maíz y caña de azúcar.
\end{abstract}

Palabras clave: Intoxicación; plaguicidas; Productos agrícolas; Goiás.

\title{
Introdução
}

Substâncias químicas cuja finalidade de controle de pragas e doenças em plantações têm registros entre os escritos gregos e romanos de há mais de 3.000 anos. No Brasil, a introdução do uso intensivo dos agrotóxicos industrializados foi incentivada pela Revolução Verde, pacote tecnológico que visava o aumento da produção e produtividade por meio, além do uso de agrotóxicos e outros insumos industrializados, da mecanização em larga escala. Esse fator de produção tinha seus gastos préestabelecidos nos financiamentos estatais (30\% dos recursos financeiros deveriam ser gastos em inseticidas e $20 \%$ em herbicidas). Neste contexto, o objetivo era promover a modernização do território, mediante a modernização do campo (agroindustrialização), para garantir o aumento da produção e da produtividade, sem considerar os riscos ao ambiente e à saúde humana.

O efeito do uso de agrotóxicos sobre a saúde humana é um problema que tem merecido a atenção da comunidade científica em todo o mundo, sobretudo, nos países emergentes, em que se observa o maior número de mortes decorrentes da exposição humana a esses agentes, pois pacotes teconológicos continuam a ser impostos, sem se considerar as condições edafoclimáticas, os processos históricos de usos do solo e da água e os saberes-fazeres das populações. 
Segundo Alves Filho (2002), o aumento dos problemas relacionados ao uso dos agrotóxicos agrícolas levou à criação da Lei dos Agrotóxicos, em 1989, a partir das demandas apresentadas pelo Ministério da Saúde. Foi implantado, então, um sistema de controle de informações toxicológicas para a investigação dos acidentes com agrotóxicos, que utiliza fichas de notificação e atendimento. Esse monitoramento tem como objetivo expor a situação das intoxicações por agrotóxicos e delimitar os campos de atuação dos governos, a fim de reduzir o número de acidentes.

Segundo dados do Sindicato Nacional das Indústrias de Defensivos Agrícolas SINDAG (2011) e projeção do Ministério da Agricultura (THEISEN, 2017), no Brasil a soja ocupa o primeiro lugar em consumo de agrotóxicos: $40 \%$ do volume total de herbicidas, inseticidas, fungicidas e acaricidas. Em segundo lugar está o milho, com $15 \%$, e a cana-de-açúcar, com $10 \%$.

Destarte, o objetivo desta pesquisa é analisar a contaminação por agrotóxicos no estado de Goiás (2005 a 2015), destacando a quantidade de intoxicações nos municípios, para, posteriormente, identificar a relação destas intoxicações com o uso e com a ocupação do solo nestes municípios, com a expansão do agronegócio da cana, da soja e do milho.

\section{Metodologia}

A coleta de dados foi realizada por meio de visitas técnicas à Biblioteca do Centro de Informação Toxicológica - CIT/GO. Foram sistematizados dados, do período de 2005 a 2015, das fichas de notificação de intoxicação por agente tóxico/agrotóxico agrícola que o CIT/GO armazena, lotado na Superintendência de Vigilância Sanitária e Ambiental - SUVISA de Goiás.

A sistematização de informações sobre mês da intoxicação, idade, sexo, município onde a intoxicação ocorreu, nome do agrotóxico, princípio ativo, finalidade do agrotóxico e circunstância da intoxicação permitiu observar que os municípios que possuem as maiores áreas plantadas com monocultivos (cana, soja e milho) também apresentam elevados índices de contaminação por agrotóxicos agrícolas. Isso confirma a tese de que os municípios que possuem maiores áreas com agronegócio são aqueles que enfrentam maiores problemas em relação à contaminação do ambiente, mas, principalmente, os maiores índices de intoxicação humana.

No Estado de Goiás, o CIT/GO foi fundado em 1986, a partir da necessidade de se ter um serviço especializado, capaz de prestar informações relacionadas a agentes tóxicos utilizados em seu território. O CIT/GO mantém Plantão de Atendimento que promove um direcionamento resolutivo do atendimento ao paciente, diminuindo, com isso, sua vulnerabilidade e a fragilidade do sistema de saúde, frente aos casos suspeitos de intoxicação. Porém, falta um atendimento posterior ao atendimento emergencial 
primário, como encaminhamento para tratamentos psicológicos ou para a assistência social, por exemplo, quando a intoxicação é uma tentativa de suicídio.

Os registros de intoxicação do CIT/GO são repassados para o Sistema Nacional de Informações Tóxico-Farmacológicas - SINITOX, por meio de planilhas eletrônicas, e este faz o armazenamento e a disponibilização das informações em anuários. Os municípios repassam fichas de notificação para o CIT/GO e também ficam responsáveis por disponibilizar tais informações de intoxicação para o SINITOX, mas, geralmente, essas fichas demoram a ser repassadas ou às vezes não são digitalizadas.

Desse modo, a melhor forma de analisar as intoxicações de um estado ou município é estudar as fichas de notificação de intoxicação armazenadas nos Centros de Informações Toxicológicas - CIT's instalados nas Superintendências de Vigilância Sanitária estaduais, como o SINITOX orienta em seu próprio site ${ }^{1}$.

Como em muitos outros casos de notificação compulsória de determinados fatos aos órgãos estatais, há uma subnotificação dos casos de contaminação por agrotóxicos, ou seja, o número de intoxicações registrado no CIT/GO é muito menor do que aquele que ocorre nas atividades agrícolas. Segundo Pires et al., (2005), a subnotificação, neste caso, é da ordem de 1 para 50, ou seja, para cada caso notificado há 50 não notificados; ainda assim, os dados disponíveis são alarmantes e necessitam ser considerados e informados à população para que medidas de proteção ao ambiente e à saúde humana sejam tomadas com urgência.

Para a elaboração dos mapas de intoxicação por agrotóxico agrícola e da relação entre população e casos de intoxicação no estado de Goiás foram utilizadas informações disponibilizadas pelo Sistema Estadual de Geoinformação de Goiás - SIEG e shapefiles criados a partir dos dados obtidos. Os dados de produção agrícola se referem aos anos de 2005, 2010 e 2015, disponibilizados pelo Instituto Mauro Borges (Instituto de Estatísticas e Estudos Socioeconômicos do Estado de Goiás). O software utilizado para a elaboração dos mapas foi o ArcGis.

\section{Intoxicação por diferentes tipos de agrotóxicos e agentes intoxicantes}

Os agrotóxicos podem ser classificados de diferentes formas: segundo a espécie de praga que se deseja controlar (inseticidas, herbicidas ou fungicidas, dentre outros); conforme o grupo químico a que pertencem (organofosforados, carbamatos, organoclorados, piretóides, bipiridílicos e mercuriais, dentre outros); conforme a toxicidade aguda (classe I, II, III, IV - de acordo com a DL50); de acordo com a carcinogênese (grupo 1, 2a $2 \mathrm{~B}$ e 3 ); e segundo o tipo de formulação (solventes, aderentes, umectantes etc.) ou apresentação (líquido, pó ou granulado).

\footnotetext{
${ }^{1} \mathrm{http} / / /$ sinitox.icict.fiocruz.br/dados-nacionais
} 
$\mathrm{Na}$ tabela 01 pode-se observar uma maior incidência de intoxicação por inseticidas e herbicidas em Goiás e uma ocorrência mínima de intoxicação por fungicida.

Tabela 01. Quantidade de pacientes intoxicados por tipo de agrotóxico em Goiás (20052015)

\begin{tabular}{c|ccccccc}
\multicolumn{2}{c}{ Inseticida } & Herbicida & Formicida & Ignorado & Fungicida & Raticida & Carrapaticida \\
\hline $\mathbf{2 0 0 5}$ & 112 & 61 & 76 & 51 & 6 & 8 & 4 \\
$\mathbf{2 0 0 6}$ & 84 & 75 & 53 & 43 & 3 & 2 & 7 \\
$\mathbf{2 0 0 7}$ & 57 & 63 & 47 & 10 & 6 & 2 & 3 \\
$\mathbf{2 0 0 8}$ & 72 & 77 & 43 & 45 & 7 & 2 & 1 \\
$\mathbf{2 0 0 9}$ & 65 & 90 & 34 & 45 & 15 & 3 & 6 \\
$\mathbf{2 0 1 0}$ & 62 & 87 & 48 & 73 & 18 & 0 & 3 \\
$\mathbf{2 0 1 1}$ & 48 & 70 & 30 & 50 & 19 & 1 & 1 \\
$\mathbf{2 0 1 2}$ & 82 & 142 & 29 & 34 & 5 & 0 & 0 \\
$\mathbf{2 0 1 3}$ & 130 & 147 & 25 & 31 & 9 & 1 & 2 \\
$\mathbf{2 0 1 4}$ & 86 & 150 & 30 & 52 & 16 & 2 & 0 \\
$\mathbf{2 0 1 5}$ & 64 & 112 & 16 & 23 & 11 & 0 & 0 \\
TOTAL & 862 & 1074 & 431 & 457 & 115 & 21 & 27 \\
Fonte: CIT/SUVISA (2016) & & & & & &
\end{tabular}

Pode-se observar também que de 2005 a 2015 há um aumento no número de notificações de intoxicação por herbicidas e, consequentemente, deve ter ocorrido uma maior utilização deste tipo de agrotóxico. De acordo com pesquisas disponíveis no "Dossiê ABRASCO: um alerta sobre os impactos dos agrotóxicos na saúde" (CARNEIRO et al., 2015), a introdução de transgênicos tolerantes a herbicidas nas lavouras brasileiras, que alcançam cerca de $50 \%$ dos 74 milhões de hectares cultivados no Brasil (IBGE, 2010), provocou um aumento do uso deste agrotóxico.

Segundo o mesmo Dossiê ABRASCO (CARNEIRO et al., 2015), 93\% da área cultivada com milho, soja e algodão são de sementes transgênicas; a cana-de-açúcar não possuía variedades transgênicas até 2016, porém, foi aprovado em junho pela Comissão Técnica Nacional de Biossegurança - CTNBio o plantio de cana-de-açúcar transgênica. Dessa forma, a utilização e a consequente intoxicação por herbicida tende a aumentar, necessitando de monitoramento e pesquisas mais aprofundadas.

Conforme as fichas investigadas, há uma incidência de intoxicação por produtos ignorados, o que deve-se ao preenchimento das fichas de forma errada e, principalmente, ao fato de pessoas intoxicadas desconhecerem o agrotóxico com que foram contaminadas. Isso exige, de imediato, capacitação dos servidores que lidam com o assunto e maciças campanhas educativas para os consumidores e trabalhadores que manuseiam esses produtos. 


\section{Circunstâncias da intoxicação}

A contaminação por agrotóxicos pode ocorrer a partir do contato com a pele, mucosas, pela respiração ou ainda por sua ingestão ou de alimentos a eles expostos, como nos diversos casos apresentados pelo Dossiê da Associação Brasileira de Saúde Coletiva - ABRASCO (CARNEIRO et al., 2015) sobre os impactos dos agrotóxicos na saúde humana. A intoxicação pode acontecer de forma ocupacional, acidental ou intencional (suicídio ou homicídio).

Grupos de profissionais que têm contato com agrotóxicos, como camponeses, funcionários de empresas rurais e até agentes públicos, por exemplo, os que fazem a aspersão de veneno para combater o Aedes aegypti, podem sofrer intoxicação ocupacional, durante a preparação do produto e/ou a aplicação e/ou devido a entrada nas lavouras após a sua aplicação. Nas aplicações aéreas, os pilotos agrícolas e seus auxiliares também são considerados como grupo de risco.

Para Sobreira; Adissi (2003), uma das causas do aumento do número de casos de intoxicação é a utilização de agrotóxicos em larga escala, tendo como consequência um grande número de mortes e doenças de trabalhadores que, inadvertidamente, tiveram contato com o produto. Mas, os agrotóxicos não atingem só natureza e a saúde de indivíduos ou grupos específicos, já que seus resíduos podem ser ingeridos através de alimentos e da água, sendo ainda potencialmente tóxicos aos seres humanos.

Pignati et al., (2014), em pesquisa sobre os impactos dos agrotóxicos na saúde, no trabalho e no ambiente em municípios brasileiros, mostrou que, em média, a utilização de agrotóxicos no estado de Mato Grosso é de dez litros por hectare. É este consumo exorbitante que faz com que o Brasil seja o campeão em consumo de agrotóxicos, no mundo, consequentemente, o que gera intoxicação do ambiente e da saúde da população.

A intoxicação acidental, pode ocorrer com as pessoas que entram em contato com os agrotóxicos em ambientes domésticos, como para repelir insetos ou na reutilização de frascos dos produtos ou por se confundir as embalagens de agrotóxicos com as de outros produtos, o que ocorre principalmente com crianças e idosos.

A intoxicação acidental pode ocorrer também pelo efeito da "deriva técnica", que é o transporte pelo vento das partículas dos agrotóxicos aplicados em uma área para outras áreas, principalmente quando a aplicação é aérea porque elas podem ser levadas a uma distância de até 32 quilômetros da área de aplicação, segundo Pimentel (1995). Residências próximas às lavouras de cana-de-açúcar, soja ou milho são as mais afetadas.

$\mathrm{Na}$ intoxicação intencional estão os casos em que os agrotóxicos são utilizados para se cometer suicídio e homicídio. A intoxicação para suicídio é a que apresenta os maiores índices de letalidade. Essa situação é grave e deve ser tratada cuidadosa e rigorosamente pela sociedade e pelo poder público como uma questão de saúde e de segurança. 
$\mathrm{Na}$ tabela 2, pode-se verificar as principais circunstâncias de intoxicação humana por agrotóxicos em Goiás no período de 2005 a 2015.

Tabela 02. Circunstâncias de Intoxicação em Goiás (2005-2015)

\begin{tabular}{|c|c|c|c|c|c|c|c|c|c|c|c|c|c|c|c|}
\hline & \multicolumn{3}{|c|}{ Acidental } & \multicolumn{3}{|c|}{ Ocupacional } & \multicolumn{3}{|c|}{ Suicídio } & \multicolumn{3}{|c|}{ Homicídio } & \multicolumn{3}{|c|}{ Alimentação } \\
\hline & $\mathrm{H}$ & M & Total & $\mathrm{H}$ & M & Total & $\mathrm{H}$ & M & Total & $\mathrm{H}$ & M & Total & $\mathrm{H}$ & M & Total \\
\hline 2005 & 48 & 24 & 72 & 87 & 12 & 99 & 90 & 50 & 140 & 2 & 0 & 2 & 3 & 2 & 5 \\
\hline 2006 & 55 & 23 & 78 & 57 & 2 & 59 & 85 & 43 & 128 & 1 & 0 & 1 & 0 & 1 & 1 \\
\hline 2007 & 39 & 10 & 49 & 60 & 0 & 60 & 54 & 23 & 77 & 0 & 0 & 0 & 2 & 0 & 2 \\
\hline 2008 & 66 & 21 & 87 & 64 & 8 & 72 & 28 & 25 & 83 & 0 & 0 & $\mathbf{0}$ & 2 & 3 & 5 \\
\hline 2009 & 71 & 9 & 80 & 63 & 6 & 69 & 80 & 26 & 106 & 0 & 0 & $\mathbf{0}$ & 2 & 1 & 3 \\
\hline 2010 & 71 & 13 & 84 & 85 & 19 & 104 & 69 & 29 & 98 & 0 & 1 & 1 & 3 & 1 & 4 \\
\hline 2011 & 24 & 8 & 32 & 100 & 10 & 110 & 51 & 24 & 75 & 0 & 0 & 0 & 1 & 1 & 2 \\
\hline 2012 & 57 & 17 & 74 & 92 & 21 & 113 & 55 & 42 & 97 & 2 & 1 & 3 & 1 & 1 & 2 \\
\hline 2013 & 77 & 31 & 108 & 128 & 27 & 115 & 62 & 45 & 107 & 2 & 0 & 2 & 5 & 7 & 12 \\
\hline 2014 & 37 & 13 & 50 & 154 & 29 & 183 & 50 & 51 & 101 & 1 & 0 & 1 & 0 & 0 & 0 \\
\hline 2015 & 45 & 12 & 57 & 89 & 5 & 94 & 41 & 33 & 74 & 0 & 0 & 0 & 1 & 0 & 1 \\
\hline TOTAL & 590 & 181 & 771 & 979 & 139 & 1078 & 665 & 391 & 1086 & 8 & 2 & 10 & 20 & 17 & 37 \\
\hline
\end{tabular}

Fonte: CIT/SUVISA (2016)

Em todos as formas de intoxicação é maior o número de homens do que de mulheres, mas principalmente na ocupacional, porque a aplicação dos agrotóxicos é realizada, predominantemente, por trabalhadores do sexo masculino.

Não obstante, há ainda a intoxicação crônica devido ao tempo de exposição aos agrotóxicos, o que provoca problemas imunológicos, hematológicos, hepáticos, neurológicos, malformações congênitas, tumores. Supõe-se que estes agravos a saúde podem acarretar, concomitantemente, depressão e isso pode elevar a ocorrência de suicídios. Tanto a depressão quanto outros transtornos psíquicos que causados pela exposição a agrotóxicos se dá especialmente pela contaminação por organofosforados, embora eles não sejam os únicos causadores deste tipo de dano à saúde humana (ARAÚJO et al., 2007; MEYER, et al., 2007).

Alguns estudos de caso realizados no Brasil indicam essa correlação de forma ainda preliminar, como é o caso do trabalho "Incidência de suicídios e uso de agrotóxicos por trabalhadores rurais em Luz/MG, Brasil" (MEYER, et al., 2007). Mas outros estudos, como o de Araújo et al., (2007), sobre a exposição de trabalhadores de Nova Friburgo/RJ a agrotóxicos, identificaram uma relação direta entre esta exposição e distúrbios psiquiátricos. 
Evidências científicas mostram que a exposição aos pesticidas pode levar a danos à saúde, muitas vezes irreversíveis, como o caso da neuropatia tardia por sobreexposição a organofosforados. As consequiências neurotóxicas da exposição aguda por altas concentrações de pesticidas também estão bem estabelecidas, seja os efeitos muscarínicos, nicotínicos e no sistema nervoso central e periférico.

A exposição também está associada a uma larga faixa de sintomas, bem como déficits significativos da performance neurocomportamental e anormalidades na função do sistema nervoso. Foram também diagnosticados $13(12,8 \%)$ quadros de neuropatia tardia e $29(28,5 \%)$ quadros de síndrome neurocomportamental e distúrbios neuropsiquiátricos associados ao uso crônico de agrotóxicos. Os resultados apontam para a ocorrência de episódios recorrentes de sobre-exposição múltipla, a elevadas concentrações de diversos produtos químicos, com grave prejuízo para as funções vitais desses trabalhadores, especialmente por se encontrarem em uma faixa etária jovem (média $=35 \pm$ 11 anos) e período produtivo da vida. Estes dados demonstram a importância do monitoramento da múltipla exposição a agrotóxicos, uma cadeia de eventos de grande repercussão na saúde pública e para o meio ambiente (ARAÚJO et al., 2007).

A pesquisa de Araújo et al., (2007) demonstra claramente que a intoxicação por agrotóxicos, provoca danos severos à saúde mental e cardiovascular, além de alertar para a gravidade da múltipla exposição a agrotóxicos. Concorda-se com os autores que a intoxicação por agrotóxicos tem consequências não apenas para a saúde das pessoas, consideradas individualmente, mas também é um caso de saúde pública e de danos ao meio ambiente, que é um bem coletivo de uso comum.

As intoxicações ocupacionais e acidentais, segundo dados do Censo Agropecuário de 2006 (IBGE, 2010), podem estar sendo provocadas porque parte dos trabalhadores rurais é analfabeta; em se tratando especificamente do estado de Goiás, são $51 \%$ de analfabetos. Embora não se possa considerar a priori que baixa escolaridade signifique pouco conhecimento, certamente ela influencia essa situação mesmo porque a esses trabalhadores não restam muitas opções no mercado de trabalho. A conscientização sobre os perigos a que se está exposto também depende do saber adquirido fora da escola. Há extenso e fecundo saber popular e tradicional (saberes-fazeres) entre os diferentes grupos de trabalhadores do campo, mas não exatamente em relação aos agrotóxicos, que são produtos recentes da civilização ocidental urbano-industrial.

Outro fato importante nessa questão da contaminação por agrotóxicos é que a assistência técnica continua muito limitada, sendo praticada em apenas $22 \%$ dos estabelecimentos - aqueles cuja área média é de 228 hectares. O Censo Agropecuário de 
2006 (IBGE, 2010) mostra que mais da metade dos estabelecimentos onde houve utilização de agrotóxicos não recebeu orientação técnica (785 mil ou 56,3\%).

A forma de aplicação dos agrotóxicos nas lavouras também é um importante fator a ser considerado na análise das intoxicações. O pulverizador costal, por exemplo, é o equipamento de aplicação que apresenta maior potencial de exposição aos agrotóxicos e é utilizado em 973 mil estabelecimentos.

O destino das embalagens vazias também é importante para a ocorrência ou não de contaminação. As embalagens vazias são queimadas ou enterradas, em 358 mil estabelecimentos, o que é um descumprimento ao Decreto 4.074, de 4 de janeiro de 2002 e à Resolução CONAMA 465 de 5 de dezembro de 2014, que dispõem sobre a destinação final das embalagens de agrotóxicos e obriga o consumidor a devolver as embalagens vazias ao estabelecimento comercial em que as adquiriu. Em 296 mil estabelecimentos os trabalhadores não utilizaram nenhum equipamento de proteção individual; já nos estabelecimentos em que os trabalhadores utilizaram, a maioria, adotou apenas botas e chapéu.

Nas fichas de notificação de intoxicação analisadas nesta pesquisa há inúmeros casos que relatam a intoxicação pelo consumo de refrigerantes ou água em recipientes que estavam contaminados por agrotóxicos, o que demonstra a total falta de cuidado no manuseio desses produtos porque a contaminação pode ocorrer, como antes discutido, de diversas formas, desde a fabricação do produto, até seu manuseio e o descarte de embalagens vazias.

Tabela 03. Os cinco agrotóxicos que mais ocasionaram intoxicações em Goiás (20052015)

\begin{tabular}{c|ccccc}
\multicolumn{1}{c}{$\mathbf{1}^{\mathbf{0}}$} & $\mathbf{2}^{\mathbf{0}}$ & $\mathbf{3}^{\mathbf{0}}$ & $\mathbf{4}^{\mathbf{0}}$ & $\mathbf{5}^{\mathbf{0}}$ \\
\hline $\mathbf{2 0 0 5}$ & Furadan & Roundup & Aldrin & $2,4-\mathrm{D}$ & K-Othrine \\
$\mathbf{2 0 0 6}$ & Roundup & Furadan & $2,4-\mathrm{D}$ & Furazin & Tamaron \\
$\mathbf{2 0 0 7}$ & Roundup & Furadan & $2,4-\mathrm{D}$ & Aldrin & Regent \\
$\mathbf{2 0 0 8}$ & Roundup & Furadan & Tamaron & Aldrin & Furazin \\
$\mathbf{2 0 0 9}$ & Roundup & Furadan & $2,4-\mathrm{D}$ & Furazin & Aldrin \\
$\mathbf{2 0 1 0}$ & Roundup & Furadan & Captan & Furazin & Volcane \\
$\mathbf{2 0 1 1}$ & Roundup & Furadan & $2,4-D$ & Aldrin & Standak \\
$\mathbf{2 0 1 2}$ & Roundup & Furadan & Regent & $2,4-D$ & Aldrin \\
$\mathbf{2 0 1 3}$ & Roundup & Regent & Furadan & $2,4-D$ & Ampligo \\
$\mathbf{2 0 1 4}$ & Roundup & Furadan & $2,4-D$ & Regent & Lannate \\
$\mathbf{2 0 1 5}$ & Roundup & Furadan & 2,4-D & Regent & Fipronil
\end{tabular}

Fonte: CIT/SUVISA (2016)

A tabela 03 destaca os agrotóxicos que mais causaram intoxicação no período entre 2005 e 2015 no estado de Goiás. Em primeiro está o Roundup (Glifosato) com 725 
casos, seguido do Furadan (Carbofuran) com 337 casos, o 2,4-D (Diclorofenociacético) com 116 casos, o Regent (Fenil-pirazol) com 64 casos, o Aldrin (Organoclorado) com 51 casos e o Furazin (Carbamato) com 34 casos.

Em pesquisa de Samsel; Seneff (2013), seus testes apontam que o glifosato, princípio ativo do Roundup, causará $50 \%$ do autismo em crianças até 2025 , e outras doenças modernas, como depressão, infertilidade, mal de Alzheimer, câncer e doenças cardíacas. O Guia de Prevenção, Notificação e Tratamento das Intoxicações por Agrotóxicos (MATO GROSSO DO SUL, 2013) aponta que os agrotóxicos com o princípio ativo Carbamato, como o Furazin, e com o Carbofuran, como o Furadam, podem provocar edema pulmonar, depressão, paralisia respiratória, perda de memória e até dificuldade motora nos intoxicados. Já os inseticidas organoclorados, como o Aldrin, podem provocar vertigem, opacificação da córnea, insuficiência respiratória, atrofia testicular, e a consequente infertilidade, e câncer. E os ácidos 2,4-Diclorofenociacético (2,4-D) causam desde irritação nos olhos e mucosas, até parada cardiorrespiratória.

Adiante, pretende-se espacializar as contaminações, mostrando as relações perigosas do agronegócio em Goiás com o ambiente e a saúde, a partir da superposição entre as áreas com as principais monoculturas (soja, milho e cana-de-açúcar) e os maiores índices de intoxicação.

\section{Distribuição espacial das intoxicações por agrotóxicos em Goiás}

Os dados coletados no CIT/GO nas fichas de notificação de intoxicações por agrotóxicos entre 2005 e 2015 foram, nesta pesquisa, localizados espacialmente em Goiás. A partir do mapa ${ }^{2}$ (Figura 1) a seguir foi possível identificar as regiões do Estado de Goiás que apresentam uma maior concentração de casos de intoxicação, buscando compreender os fenômenos por detrás dos discursos e ações que tornaram Goiás o celeiro agrícola brasileiro.

A Figura 1 mostra que a concentração dos casos de intoxicação por agrotóxicos ocorre nas áreas mais densamente ocupadas pelo agronegócio, como as regiões Sudeste, Sudoeste e Centro-Norte do Estado, além da região do entorno do Distrito Federal. É possível, portanto, estabelecer a relação entre agronegócio e contaminação por agrotóxicos de uso agrícola, o que se dá devido à quantidade desses produtos empregada nas grandes lavouras de commodities.

2 Na elaboração deste mapa, como também na discussão da questão, foram importantes os trabalhos de Larissa Mies Bombardi em "Pequeno Ensaio Cartográfico sobre o Uso de Agrotóxicos no Brasil" (BOMBARDI, 2016) e em "Geografia do Uso de Agrotóxicos no Brasil e Conexões com a União Europeia” (BOMBARDI, 2017). 


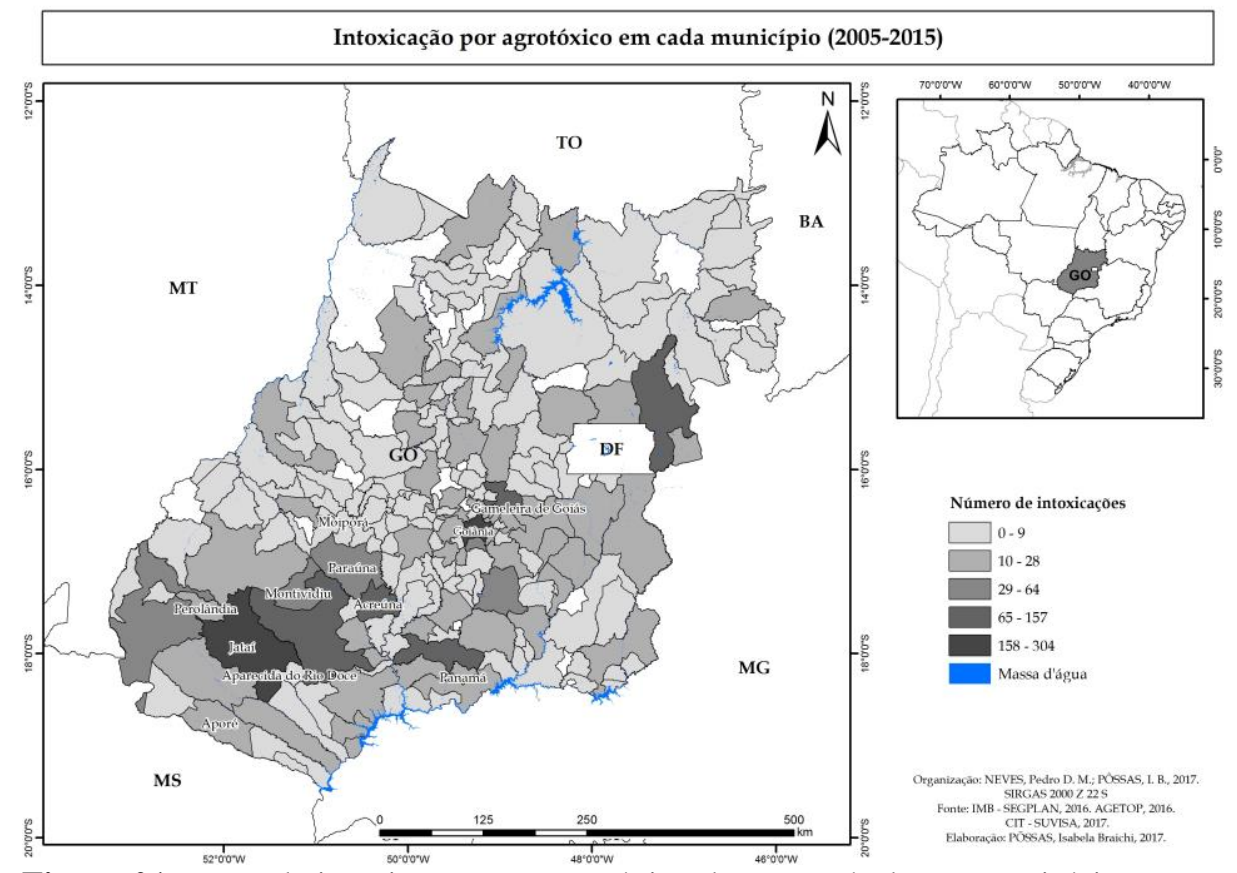

Figura 01. Mapa de intoxicação por agrotóxico de uso agrícola por município no estado de Goiás (2005-2015)

Fonte: CIT/ SUVISA (2016)

Houve 2.987 intoxicações notificadas no estado de Goiás durante o intervalo de tempo de 2005 a 2015, com maior incidência nos municípios conhecidos pela presença do agronegócio, como é o caso de Jataí (304 intoxicações), Goiânia (249), Rio Verde (157), Anápolis (155), Formosa (114), Acreúna (106), Goiatuba (104), Aparecida de Goiânia (64), Mineiros (56) e Montividiu (46).

Porém, estes dados podem camuflar a realidade, pois é importante considerar não só a quantidade de intoxicações, mas também o tamanho da população de cada município. Deste modo, deve-se fazer a relação entre o número de intoxicações e a população dos municípios, dividindo-se o último pelo primeiro; quanto menor o resultado, maior será a contaminação. De acordo com os dados do IBGE (2017), foi elaborado o quadro a seguir, que traz essa relação.

Dentre os municípios com as maiores taxas de intoxicação por habitante, estão: Aporé, com 01 intoxicação para cada 163 habitantes; Acreúna, com 01 intoxicação para cada 205 habitantes; Montividiu, com 01 intoxicação para cada 263 habitantes; Jataí, com 01 intoxicação para cada 315 habitantes; Goiatuba, com 01 intoxicação para cada 328 habitantes; e Paraúna, com 01 intoxicação para cada 329 habitantes. 
Quadro 01. Relação entre o número de intoxicações e a população dos municípios (2015) em Goiás

\begin{tabular}{|c|c|c|c|c|c|c|c|}
\hline Município & Intoxicações & Habitantes & $\begin{array}{l}\text { Relação } \\
\text { Int./hab }\end{array}$ & Município & Intoxicações & Habitantes & $\begin{array}{l}\text { Relação } \\
\text { Int./hab }\end{array}$ \\
\hline Aporé & 25 & 4077 & 163,08 & Maurilândia & 23 & 12956 & 563,30 \\
\hline Panamá & 16 & 2722 & 170,13 & $\begin{array}{l}\text { São Miguel do } \\
\text { Passa Quatro }\end{array}$ & 7 & 3987 & 569,57 \\
\hline Acreúna & 106 & 21730 & 205,00 & $\begin{array}{c}\text { Ouro Verde } \\
\text { de Goiás }\end{array}$ & 7 & 4016 & 573,71 \\
\hline Perolândia & 15 & 3105 & 207,00 & Vicentinópolis & 14 & 8171 & 583,64 \\
\hline Montividiu & 46 & 12101 & 263,07 & Barro Alto & 17 & 10031 & 590,06 \\
\hline $\begin{array}{c}\text { Aparecida } \\
\text { do Rio Doce }\end{array}$ & 9 & 2510 & 278,89 & Turvânia & 8 & 4857 & 607,13 \\
\hline Jataí & 304 & 95998 & 315,78 & $\begin{array}{l}\text { Santo Antônio } \\
\text { de Goiás }\end{array}$ & 9 & 5527 & 614,11 \\
\hline Paraúna & 34 & 11199 & 329,38 & Piracanjuba & 39 & 24772 & 635,18 \\
\hline $\begin{array}{l}\text { Gameleira } \\
\text { de Goiás }\end{array}$ & 11 & 3664 & 333,09 & Cabeceiras & 12 & 7829 & 652,42 \\
\hline Moiporá & 5 & 1704 & 340,80 & São Patrício & 3 & 2062 & 687,33 \\
\hline Santa Isabel & 11 & 3836 & 348,73 & Davinópolis & 3 & 2126 & 708,67 \\
\hline $\begin{array}{l}\text { Cachoeira } \\
\text { de Goiás }\end{array}$ & 4 & 1425 & 356,25 & Lagoa Santa & 2 & 1435 & 717,50 \\
\hline Goianápolis & 29 & 11024 & 380,14 & Castelândia & 5 & 3642 & 728,40 \\
\hline Serranópolis & 21 & 8147 & 387,95 & $\begin{array}{c}\text { Ipiranga de } \\
\text { Goiás }\end{array}$ & 4 & 2940 & 735,00 \\
\hline Itarumã & 16 & 6853 & 428,31 & $\begin{array}{l}\text { Terezópolis } \\
\text { de Goiás }\end{array}$ & 10 & 7389 & 738,90 \\
\hline Porteirão & 8 & 3670 & 458,75 & Campinaçu & 5 & 3743 & 748,60 \\
\hline $\begin{array}{l}\text { Leopoldo de } \\
\text { Bulhões }\end{array}$ & 17 & 8167 & 480,41 & Aragoiânia & 12 & 9444 & 787,00 \\
\hline Ivolândia & 5 & 2601 & 520,20 & Rianápolis & 6 & 4788 & 798,00 \\
\hline $\begin{array}{c}\text { Santo } \\
\text { Antônio da } \\
\text { Barra }\end{array}$ & 9 & 4714 & 523,78 & $\begin{array}{l}\text { São João da } \\
\text { Paraúna }\end{array}$ & 2 & 1597 & 798,50 \\
\hline $\begin{array}{c}\text { Santa Rita } \\
\text { do Novo } \\
\text { Destino }\end{array}$ & 6 & 3331 & 555,17 & Itajá & 6 & 4961 & 826,83 \\
\hline
\end{tabular}

Fonte: CIT/ SUVISA (2016); IBGE (2017)

Deste modo, foi elaborado outro mapa (Figura 2) que traz a relação entre o número de notificação de intoxicações por 100.000 habitantes (utilizando a estimativa populacional dos municípios, de acordo com o IBGE (2017) de cada município. 


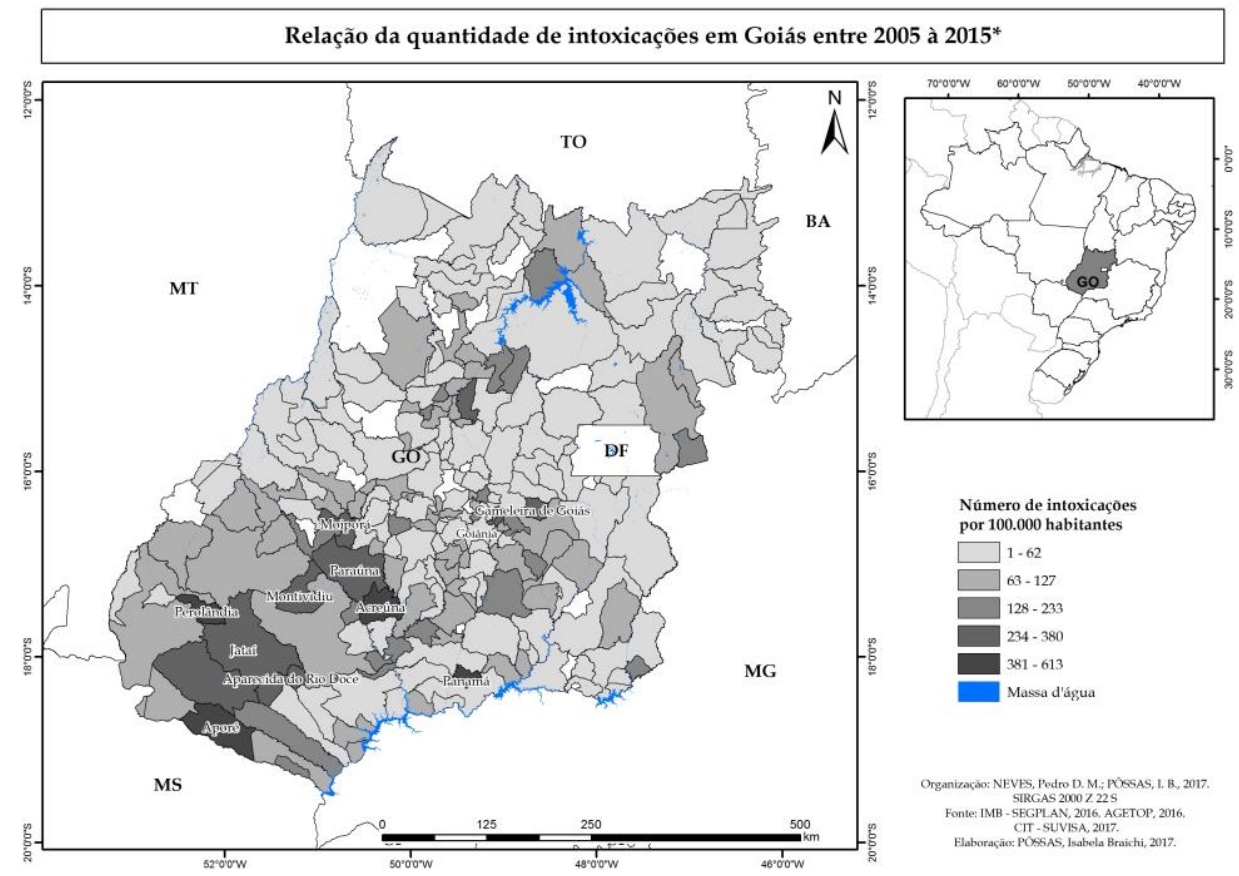

Figura 02. Mapa da relação entre população e casos de intoxicação por agrotóxico de uso agrícola nos municípios do estado de Goiás (2005-2015)

Fonte: CIT/ SUVISA (2016)

Conforme este mapa da relação entre população total e casos de intoxicação por agrotóxico (figura 2) de cada município em Goiás, destacam-se, Aporé, Panamá, Acreúna, Perolândia, Montividiu e Aparecida do Rio Doce, apesar de eles apresentarem menor quantidade de notificações por intoxicação do que municípios como Jataí.

\section{Produção agrícola e agrotóxicos}

Como, segundo Theisen (2010) e SINDAG (2017), no Brasil a soja ocupa o primeiro lugar em consumo de agrotóxicos: $40 \%$ do volume total de herbicidas, inseticidas, fungicidas e acaricidas, consequentemente, espera-se que haja maior número de contaminações em municípios com maiores cultivos de soja.

Para melhor se compreender a relação entre a de intoxicação por agrotóxico e os diferentes cultivos foram desenvolvidos mapas que mostram a expansão e territorialização dos principais cultivos em Goiás: cana-de-açúcar, milho e soja. Deste modo, é possível observar que ocorrem mais casos de intoxicações por agrotóxico onde há a predominância de determinado monocultivo. 
No caso da cana-de-açúcar, como mostra a figura 3, há um predomínio inicial (2005) deste cultivo na Mesorregião Centro de Goiás e uma posterior (2010) expansão para a Mesorregião Sul Goiano. Em 2006, foi lançado e implementado o Plano Nacional de Agroenergia (2006/2011), que favoreceu o aumento do cultivo de cana-de-açúcar no Estado.
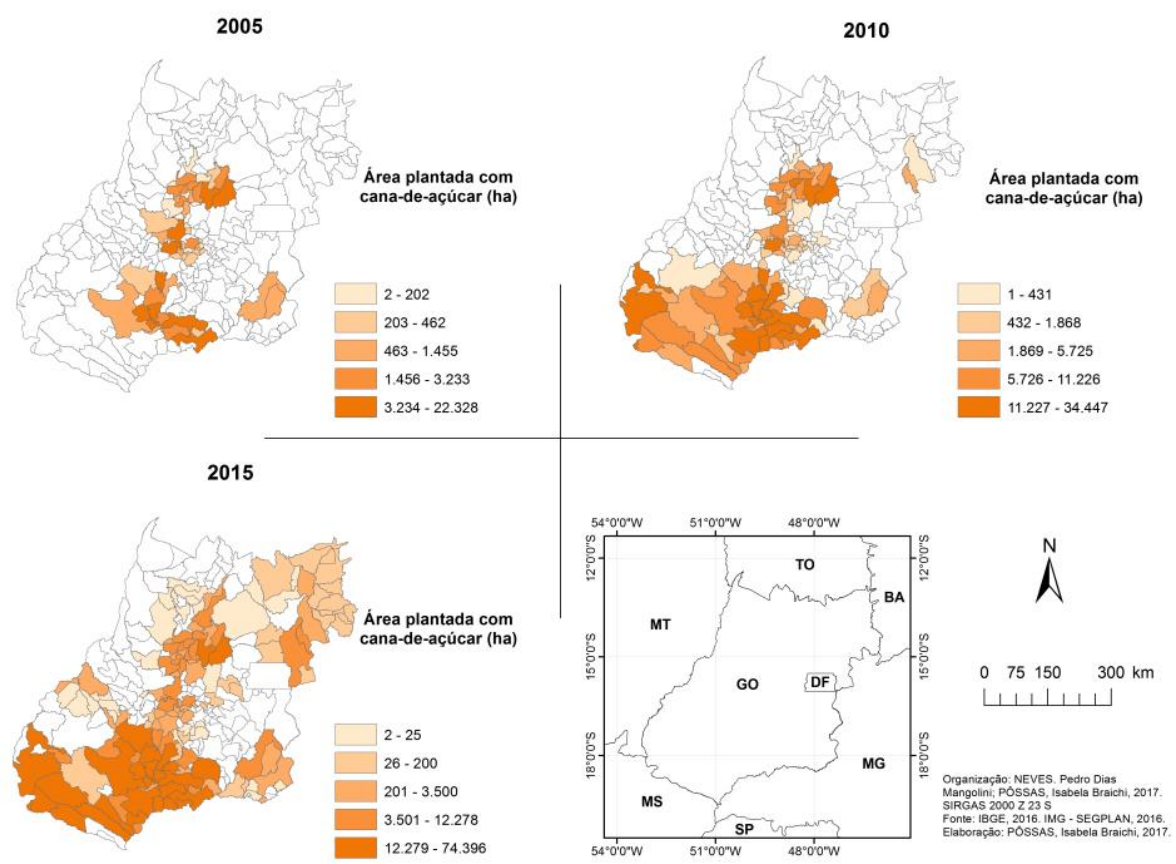

Figura 03. Mapa da evolução histórica (2005/2010/2015) da área plantada com cana-deaçúcar

Fonte: IBGE, 2016; IMG - SEGPLAN, 2016.

Goiás apresenta diversos fatores que facilitaram os investimentos no agronegócio canavieiro e a atração de uma grande quantidade de agroindústrias. Dentre eles podem-se enumerar: a) disponibilidade de terras férteis para arrendamento/aquisição; b) preço de terras relativamente baixo; c) disponibilidade hídrica; d) localização geográfica que facilita o escoamento da produção; e) fatores edafoclimáticos propícios para o plantio da cultura; f) abundância de terras com topografia planas, o que facilita a colheita mecanizada; g) disponibilidade de mão de obra para grandes colheitas manuais; h) e disponibilidade de incentivos fiscais propiciados pelo governo estadual para implantação de novas plantas industriais, 
especialmente com recursos do Fundo Constitucional de Financiamento do Centro-Oeste - FCO e do Banco Nacional de Desenvolvimento Econômico e Social - BNDES.

No Brasil, o cultivo da soja foi incentivado pela crise na oferta de proteínas vegetais no final da década de 1970. A produção desses grãos expandiu-se para regiões que até então não tinham tradição na sua produção (IGREJA et al., 1988). Além de a implementação do cultivo de soja provocar mudanças no uso e cobertura do solo no Estado de Goiás, elevou-se a concentração fundiária e reduziu-se a necessidade de mão de obra no campo, mediante a introdução de máquinas e insumos químicos (RIBEIRO et al., 2002).

A figura 4 mostra a expansão do cultivo da soja em Goiás entre 2005 e 2015 e permite identificar as regiões de maior concentração da produção em Goiás (Figura 4). O cultivo de soja concentrava-se, em 2005, no Sul do Estado, com alguns núcleos no Norte e Leste. Em 2010, a distribuição permanece praticamente a mesma, mas a quantidade de hectares plantados aumenta. Já em 2015, a produção avança para o Norte, enquanto o agronegócio canavieiro se expande na Mesorregião Sul Goiano.

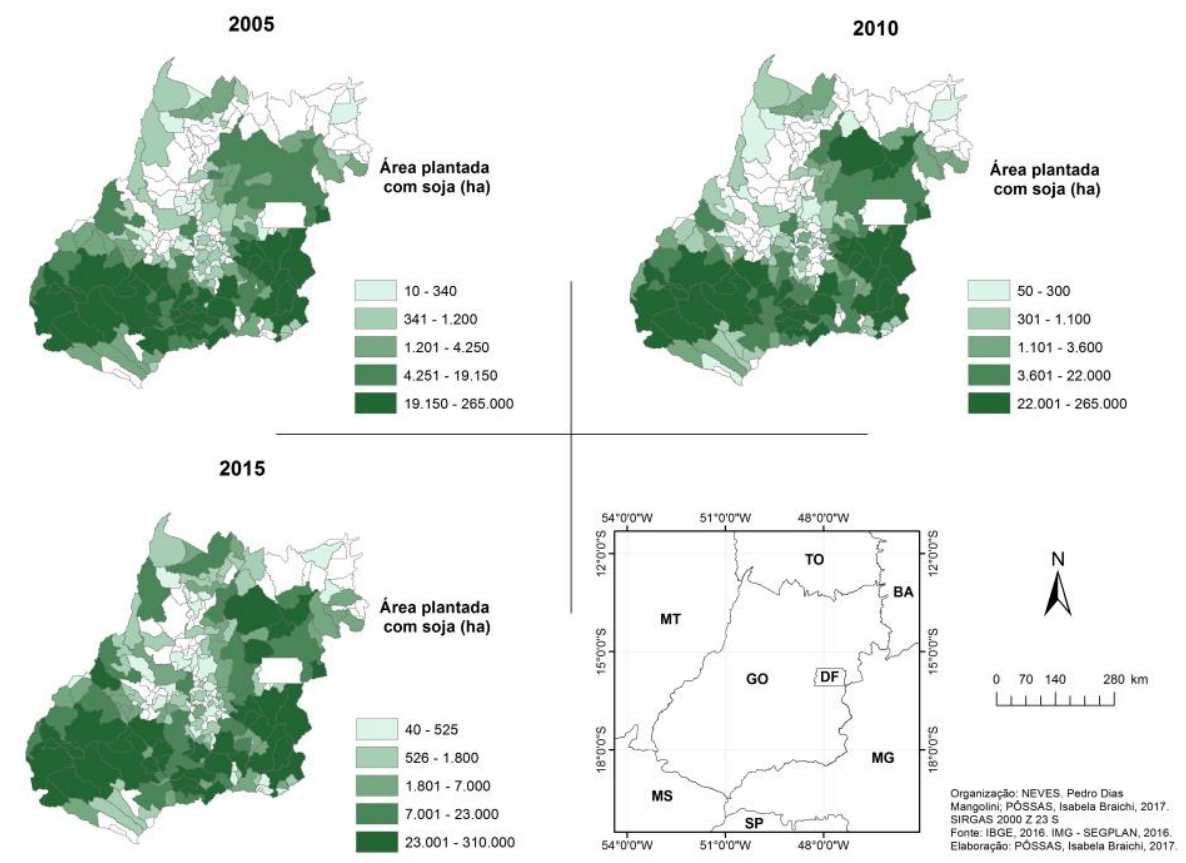

Figura 04. Mapa da evolução histórica (2005/2010/2015) da área plantada com soja (em ha) em Goiás.

Fonte: IBGE (2016); IMB - SEGPLAN (2016) 
As áreas que apresentam a maior quantidade de plantação de soja, são as mesmas onde há grande quantidade de notificações por intoxicação, como Jataí e Rio Verde, o que evidencia uma relação direta entre agronegócio e intoxicação por agrotóxicos.

Já o cultivo do milho, tanto em 2005 quanto em 2010, permanece concentrado nas Mesorregiões do Sul Goiano e Leste de Goiás, sem grande alteração na sua produção ao longo do tempo, como pode ser observado na figura 5. Mas, em 2015, a Mesorregião Noroeste de Goiás apresenta uma diminuição na produção do milho.
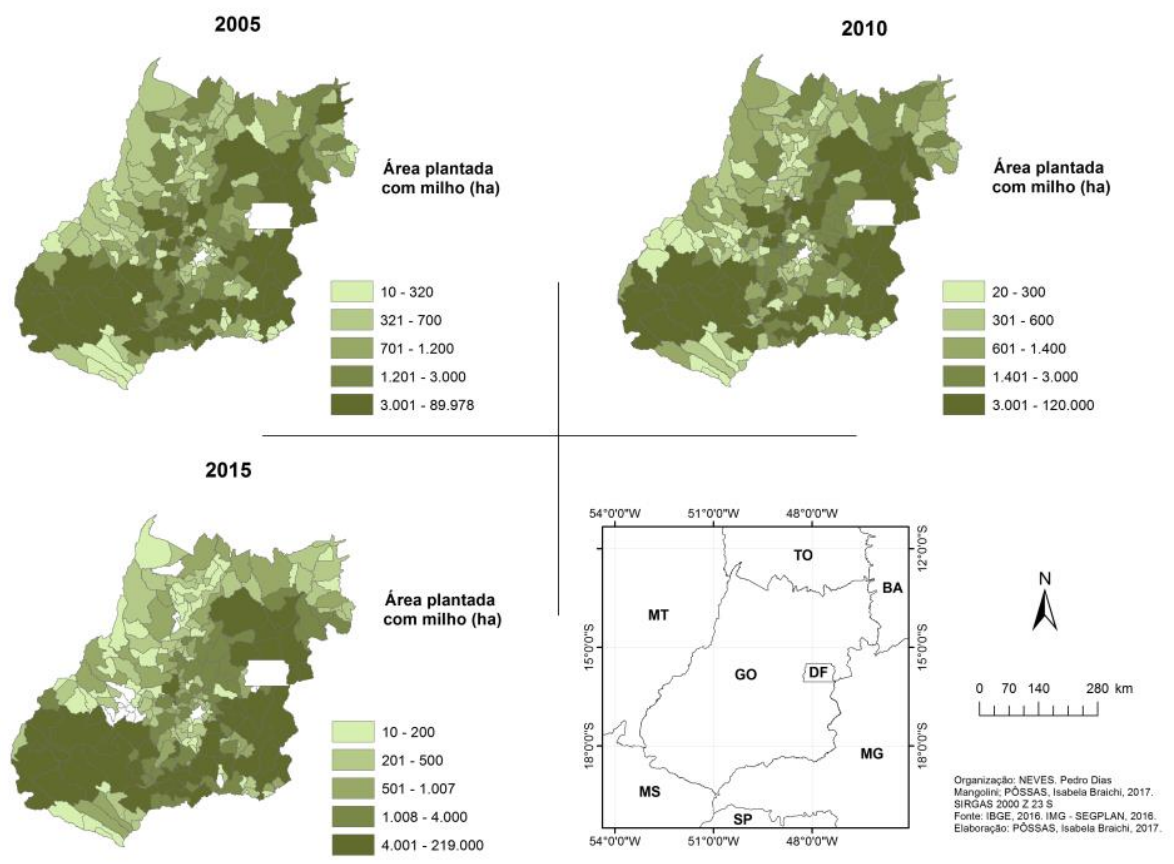

Figura 051. Mapa da evolução histórica (2005/2010/2015) da área plantada com milho (em ha)

Fonte: IBGE (2016); IMB - SEGPLAN (2016)

Para melhor se compreender a relação entre a quantidade de casos de intoxicações e os diferentes cultivos no Estado de Goiás foi elaborada a tabela 4 com as áreas plantadas com cada cultura nos municípios e os números de intoxicação. 
Tabela 04. Área plantada com cana, soja e milho nos municípios com maiores casos de intoxicação por habitante do estado de Goiás (2015)

\begin{tabular}{ccccc}
\hline Municípios & Área de Cana (ha) & Área de Soja (ha) & Área de Milho (ha) & $\begin{array}{c}\text { Notificações } \\
\text { de } \\
\text { Intoxicação }\end{array}$ \\
\hline Aporé & 17.700 & 4.000 & 11.000 & 25 \\
\hline Panamá & 4.250 & 5.000 & 1.100 & 16 \\
\hline Acreúna & 26.700 & 50.000 & 11.000 & 106 \\
\hline Perolândia & 7.000 & 55.000 & 36.000 & 15 \\
\hline Montividiu & 7.400 & 125.000 & 85.800 & 46 \\
\hline Aparecida do Rio & ----- & 1.000 & 100 & 304 \\
\hline Doce & 180 & 285.000 & 219.000 & 34 \\
\hline Jataí & 14.500 & 103.500 & 40.800 & 11 \\
\hline Paraúna & ----- & 50.000 & 6.800 & 5 \\
\hline Gameleira de Goiás & ----- & 500 & $---1 .-$ & 2987 \\
\hline Moiporá & 911.847 & 3.263 .118 & 1.409 .102 & \\
\hline GOIÁS & & &
\end{tabular}

Fonte: Produção Agrícola Municipal - IBGE (2016)

O consumo de agrotóxicos é maior nos municípios com maiores áreas plantadas com soja e isso leva esses municípios a terem maior número de notificações de intoxicação por agrotóxico, embora considerando-se também as áreas plantadas, com cana-de-açúcar e milho, a ordem das notificações possa variar um pouco.

Porém, com o início, em junho de 2017 do cultivo de cana-de-açúcar transgênica, possivelmente a quantidade de agrotóxicos utilizados neste setor aumentará, impactando ainda mais o ambiente e os seres vivos.

\section{Considerações Finais}

Este artigo objetiva contribuir com os estudos sobre as consequências do uso dos agrotóxicos no Estado de Goiás, identificando os municípios com maior número total de casos de intoxicação registrados e maior intoxicação em relação às suas populações e buscando compreender os processos causadores de tais intoxicações. É sabido que culturas como soja e cana-de-açúcar utilizam quantidades de agrotóxicos 
acima dos autorizados pela Agência Nacional de Vigilância Sanitária - ANVISA, sendo, portanto, atividades de grande impacto, tanto para o ambiente quanto para a saúde humana.

Nas fichas de notificação de intoxicações por agrotóxicos há o dado "Evolução do caso", em que se nota que o sujeito intoxicado teve óbito, cura, cura com sequela, óbito por outra causa. Das 2.987 notificações, 113 pessoas foram a óbito, 98 pessoas foram curadas, mas ficaram com sequelas e 2.774 foram tidas como "curadas". Porém, deve-se ressaltar que os efeitos crônicos (de longa duração) dos agrotóxicos não são registrados, como ressalta Bochner (2007), até mesmo por estes efeitos demorarem a se manifestar. De acordo com pesquisas contidas no "Dossiê ABRASCO. Um alerta sobre os impactos dos agrotóxicos na saúde. Parte 1 - Agrotóxicos, Segurança Alimentar e Saúde" (CARNEIRO, et al., 2012), estes efeitos crônicos podem ocorrer meses, anos ou até décadas após a exposição, manifestando-se em forma de várias doenças como cânceres, malformação congênita, distúrbios endócrinos, neurológicos e mentais.

Os dados e análises apresentadas necessitam ser aprofundadas com pesquisas de natureza transdisciplinar, pois o que foi constatado até o momento causa preocupação, diante da desinformação, aparentemente proposital, sobre os efeitos dos agrotóxicos no ambiente e na saúde, da ineficácia dos órgãos fiscalizadores e do não enfrentamento de que há uma relação direta entre a expansão do agronegócio e o aumento das intoxicações por agrotóxicos.

\section{Referências}

ALVES FILHO, José Prado. Uso de Agrotóxicos no Brasil - Controle Social e Interesses Corporativos. $1^{a}$ ed. São Paulo: Annablume; Fapesp, 2002.

ANVISA - Agência Nacional de Vigilância Sanitária. UFPR sobre Mercado e Regulação de Agrotóxicos. Brasília: ANVISA, 2012.

ARAÚJO, Alberto José de; LIMA, Jaime Silva de; MOREIRA, Josino Costa; JACOB, Silvana do Couto; SOARES, Mônica de Oliveira; MONTEIRO, Marcos César Monassa; AMARAL, Alexandre Muza do; KUBOTA, Alexandre; MEYER, Armando; COSENZA, Carlos Alberto Nunes; NEVES, Cesar Das; MARKOWITZ, Steven. Exposição múltipla a agrotóxicos e efeitos à saúde: estudo transversal em amostra de 102 trabalhadores rurais, Nova Friburgo, RJ. Ciência e Saúde Coletiva, Manguinhos/RJ, v. 12, n. 1, p. 115- 130, 2007.

BOCHNER, Rosany. Sistema Nacional de Informações Tóxico-Farmacológicas SINITOX e as intoxicações humanas por agrotóxicos no Brasil. Ciência e Saúde Coletiva, Manguinhos/RJ, v. 12, n. 1, p. 73-89, 2007.

BOMBARDI, Larissa Mies. Pequeno Ensaio Cartográfico sobre o Uso de Agrotóxicos no Brasil. São Paulo: Laboratório de Geografia Agrária USP/Blurb (Ebook), 2016. 
BOMBARDI, Larissa Mies. Geografia do Uso de Agrotóxicos no Brasil e Conexões com a União Europeia. São Paulo: FFLCH-USP, 2017.

CARNEIRO, Fernando Ferreira; PIGNATI, Wanderley RIGOTTO, Raquel Maria; AUGUSTO, Lia Giraldo da Silva; RIZOLLO, Anelisse; MULLER, Neice. Dossiê ABRASCO: Um alerta sobre os impactos dos agrotóxicos na saúde. Parte 1 Agrotóxicos, Segurança Alimentar e Saúde. Rio de Janeiro: ABRASCO, 2012.

CARNEIRO, Fernando Ferreira; RIGOTTO, Raquel Maria; AUGUSTO, Lia Giraldo da Silva; FRIEDRICH, Karen; BÚRIGO, André Campos (Orgs.). Dossiê ABRASCO: um alerta sobre os impactos dos agrotóxicos na saúde. Rio de Janeiro: Escola Politécnica de Saúde Joaquim Venâncio/FIOCRUZ; São Paulo: Expressão Popular, 2015.

MAPA - MINISTÉRIO DA AGRICULTURA, PECUÁRIA E ABASTECIMENTO. Projeções do agronegócio de 2009/10 a 2019/2020. Brasília: Mapa/AGE/ACS, 2010.

IBGE - Instituto Brasileiro de Geografia e Estatísticas. Censo Agropecuário 2006. Brasília/Rio de Janeiro: IBGE, 2010.

IBGE - Instituto Brasileiro de Geografia e Estatística. Estimativas populacionais para municípios e para as Unidades da Federação brasileiras em 2015. Disponível em: <http://www.ibge.gov.br/home/estatistica/populacao/estimativa2015/estimativa_dou.sht m>. Acesso em: mar. 2017.

IBGE - Instituto Brasileiro de Geografia e Estatísticas. Levantamentos da Produção Agrícola Municipal. Rio de Janeiro: IBGE, 2016. Disponível em: <www.sidra.ibge.gov.br>. Acesso: fev. 2017.

IGREJA, Abel Ciro Minniti; PACKER, Maria de Fátima; ROCHA, Marina Brasil. A evolução da soja no estado de Goiás e seu impacto na composição agrícola. São Paulo: Instituto de Economia Agrícola, 1988.

IMB/SEGPLAN - Instituto Mauro Borges/Secretaria de Estado de Gestão e Planejamento. Produto Interno Bruno Municipal. Disponível em: <http://www.imb.go.gov.br/>. Acesso em: set. 2016.

MATO GROSSO DO SUL. Centro Integrado de Vigilância Toxicológica - Centro Estadual de Referência em Saúde do trabalhador. Guia de prevenção, notificação e tratamento das intoxicações por agrotóxicos. (Orgs.) Flávia Luiza de Almeida Lopes e Claudia Santini de Oliveira. Campo Grande: CIVITOX/CEREST, 2013.

MEYER, Tufi Neder; RESENDE, Ione Lamounier Camargos; ABREU, Juscélio Clemente de. Incidência de suicídios e uso de agrotóxicos por trabalhadores rurais em Luz (MG), Brasil. Revista Brasileira de Saúde Ocupacional, São Paulo, v. 32, n. 116, p. 24-30, 2007.

PIGNATI, Wanderlei; OLIVEIRA, Noemi Pereira; SILVA, Ageo Mário Cândido. Vigilância aos agrotóxicos: quantificação do uso e previsão de impactos na saúde- 
trabalho-ambiente para os municípios brasileiros. Ciência e Saúde Coletiva, Manguinhos/RJ, v. 19, n. 12, p. 4669-4678, 2014.

PIMENTEL, David. Amounts of pesticides reaching target pests: environmental impacts and ethics. Journal of Agricultural and Environmental Ethics, Gainesville/EUA, v. 8, n. 1, p. 25, 1995.

PIRES, Dario Xavier; CALDAS, Eloísa Dutra; RECENA, Maria Celina Piazza. Uso de agrotóxicos e suicídios no Mato Grosso do Sul, Brasil. Caderno de Saúde Pública, Rio de Janeiro, n. 21, v. 2, p. 598-605, mar-abr, 2005.

RIBEIRO, Dinalva Donizete; MENDONÇA, Marcelo Rodrigues; HESPANHOL, Antônio Nivaldo. Relações de trabalho na agricultura mecanizada: a monocultura da soja em Goiás. Scripta Nova, Barcelona/Espanha, v. 6, n. 119, 2002.

SAMSEL, Anthony; SENEFF, Stephanie. Glyphosate's Suppression of Cytochrome P450 Enzymes and Amino Acid Biosynthesis by the Gut Microbiome: Pathways to Modern Diseases. Entropy, Basileia/Suíça, v. 15, n. 4, p. 1416-1463, 2013.

SINDAG - SINDICATO NACIONAL DAS INDÚSTRIAS DE DEFENSIVOS AGRÍCOLAS. Dados de produção e consumo de agrotóxicos, 2011. Disponível em: <www.sindag.com.br>. Acesso: fev. 2017.

SINDIVEG - SINDICATO NACIONAL DA INDÚSTRIA DE PRODUTOS PARA DEFESA VEGETAL. BALANÇO 2015 - Setor de agroquímicos confirma queda de vendas. São Paulo: SINDIVEG, 2015.

SOBREIRA, Antônio Elísio Garcia; ADISSI, Paulo José. Agrotóxicos: Falsas Premissas e Debates. Ciência e Saúde Coletiva, Manguinhos/RJ, v. 8, n. 4, p. 985-990, 2003.

THEISEN, Giovani. O Mercado de agroquímicos. 2010. Disponível em: <http://www.cnpsa.embrapa.br/met/images/arquivos/15MET/mercadoagroquimico.pdf $>$. Acesso em: abril. 2017.

Agradecimentos: à CAPES - Coordenação de Aperfeiçoamento de Pessoal de Nível Superior pelo apoio financeiro e concessão de bolsas.

Pedro Dias Mangolini Neves

Mestre em Geografia pela Universidade Estadual de Maringá - UEM.

Membro do Grupo de Pesquisa Trabalho, Território e Políticas Públicas - TRAPPU e

do Laboratório de Estudos e Pesquisas das Dinâmicas Territoriais - LABOTER

Rua Duque de Caxias, 250, ap. 106 - CEP 38.022-180 - Uberaba/MG

pmangolini@hotmail.com

Ateliê Geográfico - Goiânia-GO, v. 12, n. 2, ago/2018, p. 228-248 


\section{Marcelo Rodrigues Mendonça}

Doutor em Geografia pela Universidade Estadual Paulista - UNESP campus de Presidente Prudente e Docente do Programa de Pós-Graduação em Geografia da Universidade Federal de Goiás - UFG

Coordenador do Grupo de Pesquisa Trabalho, Território e Políticas Públicas TRAPPU e membro do Laboratório de Estudos e Pesquisas das Dinâmicas Territoriais - LABOTER

Av. Esperança s/n - IESA - Sala 06 - CEP: 74.690-900 - Campus Samambaia, Goiânia.

ufgmendonca@gmail.com

Recebido para publicação em dezembro de 2017

Aprovado para publicação em março de 2018 